\title{
Experimental Study on the Law of Deformation and Fracture of the Coal Floor in Mining above Aquifer
}

\author{
LI Zhen-hua ${ }^{1, *}$, LI Long-fei ${ }^{1}$, ZHAI Chang-zhi ${ }^{1}$ and Kumuri Toery ${ }^{2}$ \\ ${ }^{1}$ School of Energy Science \& Engineering, Henan Polytechnic University, Jiaozuo, Henan 454000, China \\ ${ }^{2}$ Kyushu Sangyo University, 3-1 Matsukodai 2-chome, Higashi-ku, Fukuoka, Japan
}

Received 3 May 2014; Accepted 14 September 2014

\begin{abstract}
As the depth of coal mining in China increases, the dangerous break-up and the water inrush of the working face floor above aquiver show an increasing trend year by year. In this paper we investigate the working face floor of the Hedong Coalfield Shuangliu Coal Mine, and obtain the distribution characteristics of the aquifers under it by analyzing the hydrogeological data. We then employ a specially-designed working face floor water pressure simulation device to conduct simulation tests of the instability characteristics of the floor fracture during the mining process, and obtain the floor stress and displacement change laws for the working face. Finally, we employ the 'plate model' theory to calculate the maximum failure depth of the working face floor rock strata of the Shuangliu Mine. The results of the simulation test show that under the joint action of mining and aquifer water pressure, the floor failure regions are mainly concentrated in the coal walls and the area below the cut-holes, and the relief of the confined water pressure through mining can be simulated by using the new confined water simulation device.
\end{abstract}

Keywords: Mining Engineering; Mining above Aquifer; Floor Failure; Simulation Test; 'Plate Model' Theory

\section{Introduction}

In order to study the failure mechanism of the mining working face floor above aquifer, researchers around the world have undertaken many theoretical and experimental studies, and have found that a laboratory simulation test is one of the most effective ways of studying the failure mechanism of the mining working face floor above aquifer [1-8]. The key to the simulation test is the selection of a confined water device. At present the confined water bags to which the water pressure is applied are used mostly to simulate the underlying aquifer of the rock strata [9]. The production cycle of these devices is quite long, and they are difficult to seal, so it is not easy to control the pressure. Furthermore, the pressure relief characteristics of the confined water cannot be simulated after the floor has been damaged.

In this paper, we investigate the mining working face of the Hedong Coalfield Shuangliu Coal Mine lower coal group, and obtain the distribution characteristics of the confined water aquifers of the mining working face floor by analyzing the hydrogeological data. We then use a working face floor water pressure simulation device designed by ourselves to conduct the simulation test of the instability characteristics of floor failure in the process of mining the working face above aquifer, and we obtain the floor stress and the stress change law for the mining process of mining the working face. Finally, we use the 'plate model' theory to calculate the maximum failure depth of the rock strata of the working face floor for the Shuangliu Mine lower coal group.

\section{Project overview}

Shuangliu Mine is located in the centre of the Hedong Coal Field of Shanxi Province. The main mining seams are the No.3, No.4, No.8 and No.9 coal seams. To date the Permian System Shanxi Formation upper coal group No. 3 and No. 4 coal seams have been mined. However, to effectively exploit the resources and achieve sustainable development of the Shuangliu Mine, it has been decided to mine the Carboniferous System Upper Series Taiyuan Formation lower coal group No.8 and No.9 coal seams. The mining of the lower coal group is mainly threatened by a roof aquifer and the floor aquifer. The roof aquifer consists mainly of Carboniferous System Upper Series Taiyuan Formation L1L5 limestone water; the water abundance is low, and it has little impact on the normal mining of the lower coal group when drainage and pressure-reduction measures are undertaken, so it is not addressed in this paper. The aquifer under the lower coal group floor consists mainly of the confined aquifers in the fissures of the Ordovician System carbonate rock class karst, and the water pressure is $6 \mathrm{MPa}$. The abundance of water is greatest in the Shangmajiagou Formation, followed by the Fengfeng Formation, and the maximum water inflow of the unit reaches $2.838 \mathrm{~L} / \mathrm{s} \cdot \mathrm{m}$.

The thickness of the aquifuge from the lower coal group floor to the Ordovician System limestone top interface is

\footnotetext{
* E-mail address: jzlizhenh@163.com

ISSN: 1791-2377 @ 2014 Kavala Institute of Technology. All rights reserved.
} 
$58.74-77.15 \mathrm{~m}$. The average thickness is $64.32 \mathrm{~m}$, and it is mainly composed of sandy mudstone, mudstone, aluminum (carbon) mudstone and sandstone. The lower coal group water-bursting coefficient is calculated to be $0.093 \mathrm{MPa} / \mathrm{m}$, which is less than the critical water-bursting coefficient 0.1 $\mathrm{MPa} / \mathrm{m}$, and thus under normal circumstances there is no water-bursting risk in the mining of the lower coal group.

\section{Simulation test}

\subsection{Simulation proportion determination}

According to the principles of similarity tests, and in combination with the actual situation of the test, the proportions are determined as follows:

1) Geometric similarity:

$$
a_{l}=l_{m} / l_{p}=1 / 100
$$

where $a_{l}$ is the geometric similarity ratio, $l_{m}$ is the model size, and $l_{p}$ is the prototype size.

2) Time similarity:

$$
a_{t}=t_{m} / t_{p}=\sqrt{a_{l}}=\sqrt{1 / 100}=1 / 10
$$

where $a_{t}$ is the time similarity ratio, $t_{m}$ is the model working face mining time, and $t_{p}$ is the prototype working face mining time.

3) Bulk density similarity coefficient:

$$
a_{\gamma}=\gamma_{m} / \gamma_{p}=1 / 1.5
$$

where $a_{\gamma}$ is the bulk density similarity ratio, $\gamma_{m}$ is the model bulk density, and $\gamma_{p}$ is the prototype bulk density.

4) Elastic modulus and strength similarity:

$$
a_{E}=a_{\sigma}=a_{r} \times a_{l}=1 / 150
$$

where $a_{E}$ and $a_{\sigma}$ are respectively the elastic modulus similarity ratio and uniaxial compressive strength similarity ratio.

The actual model production materials mainly include sand, gypsum, lime, mica, borax and water. The detailed

\begin{tabular}{|c|c|c|c|c|c|c|c|c|}
\hline $\begin{array}{l}\text { Rock } \\
\text { strata }\end{array}$ & Lithology & Prototype/m & Model/cm & Sand $/ \mathbf{k g}$ & Lime/kg & Gypsum/kg & Water/kg & Ratio No. \\
\hline 16 & Sandstone & 4.8 & 4.8 & 63.2 & 3.2 & 7.4 & 8.2 & $6: 0.3: 0.7$ \\
\hline 15 & Mudstone & 4 & 4 & 50.3 & 3.8 & 8.8 & 6.9 & $4: 0.3: 0.7$ \\
\hline 14 & Sandstone & 9.5 & 9.5 & 125 & 6.3 & 14.6 & 16.2 & $6: 0.3: 0.7$ \\
\hline 13 & $4 \#$ coal seam & 3.6 & 3.6 & 22.1 & 2.2 & 0.9 & 2.8 & $7: 0.7: 0.3$ \\
\hline 12 & Mudstone & 6 & 6 & 79 & 6.6 & 6.6 & 10.2 & $6: 0.5: 0.5$ \\
\hline 11 & $\mathrm{~K}$ sandstone & 10 & 10 & 122.9 & 21.5 & 9.2 & 17.1 & $4: 0.3: 0.7$ \\
\hline 10 & Sandy mudstone & 8 & 8 & 96.5 & 4.8 & 11.3 & 12.5 & $6: 0.3: 0.7$ \\
\hline 9 & Limestone & 10 & 10 & 115.2 & 11.5 & 26.9 & 17.1 & $3: 0.3: 0.7$ \\
\hline 8 & Sandstone & 22 & 22 & 289.6 & 14.5 & 33.8 & 37.5 & $6: 0.3: 0.7$ \\
\hline 7 & Limestone & 11.4 & 11.4 & 131.3 & 13.1 & 30.6 & 19.4 & $3: 0.3: 0.7$ \\
\hline 6 & $8 \#$ coal seam & 3 & 3 & 18.5 & 1.8 & 0.8 & 2.3 & $7: 0.7: 0.3$ \\
\hline 5 & Mudstone & 7 & 7 & 92.1 & 7.7 & 7.7 & 11.9 & $6: 0.5: 0.5$ \\
\hline 4 & 9\# coal seam & 3.7 & 3.7 & 22.8 & 2.3 & 1 & 2.9 & $7: 0.7: 0.3$ \\
\hline 3 & $\begin{array}{l}\text { Sandy mudstone } \\
\text { interbed }\end{array}$ & 23 & 23 & 296.2 & 12.7 & 29.6 & 37.6 & $7: 0.3: 0.7$ \\
\hline 2 & K sandstone & 3 & 3 & 36.9 & 2.8 & 6.5 & 5.1 & $4: 0.3: 0.7$ \\
\hline 1 & $\begin{array}{l}\text { Almandine rock } \\
\text { section }\end{array}$ & 9 & 9 & 103.7 & 10.4 & 24.2 & 15.4 & $3: 0.3: 0.7$ \\
\hline Total & & 138 & 138 & 1665.3 & 125.2 & 219.9 & 223.1 & \\
\hline
\end{tabular}
parameters and ratios of the model materials are shown in Tab. 1.

Table 1.Model parameters and ratios

\subsection{Similar simulation test bench construction}

The model test bench is composed of three major systems, namely the frame system, the loading system and the test system. The size of the frame system is $1.6 \times 0.4 \times 1.6 \mathrm{~m}$ (length $\times$ width $\times$ height). The loading system is divided into the top and bottom water pressure loading systems. The loading is applied at the model top by evenly distributing the hydraulic pressure to 36 rectangular plates. For the loading at the bottom, 20 elastic pressure springs are placed within a steel plate welded to 20 pipe slots, while the elastic pressure spring tops are welded to loading plates, which are used to simulate the water pressure. This type of loading method can not only effectively simulate the vertical load generated by the confined water for the floor rock strata, but can also simulate the characteristics of the local reduction of water pressure following the rise of the confined water (see Fig. 1). DH3818 type static strain testers and BX-1 type pressure sensors are used in the test system. Five pressure sensors were buried at depths of 10 and $20 \mathrm{~cm}$ in the lower coal group floor. The spacing between adjacent sensors was 20 $\mathrm{cm}$, and they were numbered in succession. The data from the pressure sensors were recorded for each excavation so as to measure the pressure change in the floor. A total of six groups, with 15 displacement observation points for each 
group, were arranged at the front of the model. The observation point arrangement is shown in Fig. 2.

After the simulation of the water pressure loading has become stable it is possible to simulate mining. First the No.8 coal seam was mined, then No.9. In the excavation process, the lower coal group floor rock mass stress, displacement and failure conditions were observed. The excavation was started where the model is $40 \mathrm{~cm}$ away from the left side of the boundary, and the excavation advanced forward at a step distance of $5 \mathrm{~cm} / 100 \mathrm{~min}$, equivalent to the working face advancing by $5 \mathrm{~m}$ each day. During the test the working face advanced by a total of $80 \mathrm{~cm}$, the long-wall coal mining method was used and a total of 16 step distance excavations were conducted in the test.

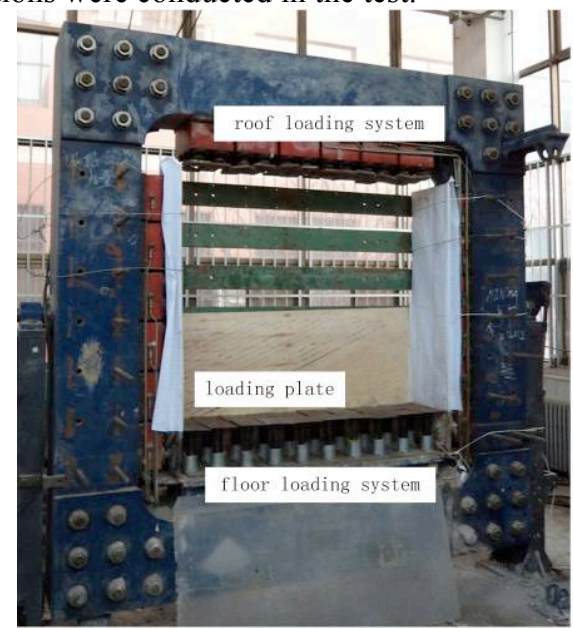

Fig.1. Similar simulation test bench

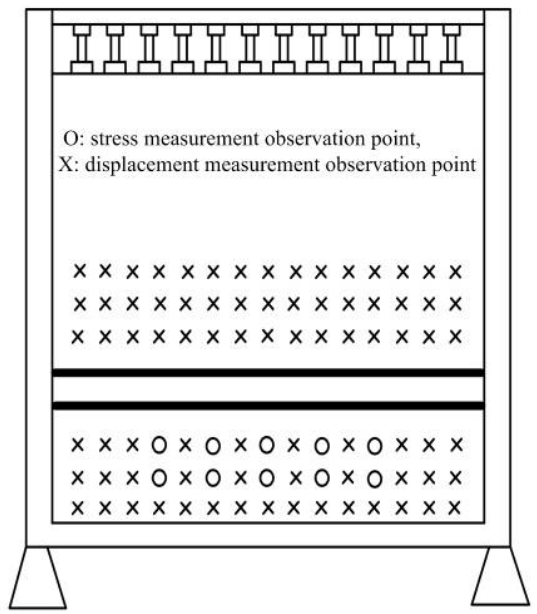

Fig.2. Observation point arrangement plan

3.3 Floor stress measurement results and their analyses As shown in Fig. 3, in the mining process of the No.8 coal seam, with increasing advance of the working face, the vertical stress in the lower coal group floor exhibits three stages: 'increased stress', 'decreased stress' and 'gradually stable'. The maximum value of the vertical stress in the rock mass at the depth of $20 \mathrm{~m}$ below the floor is $2.4 \mathrm{MPa}$, and that at a depth of $10 \mathrm{~m}$ is about $4 \mathrm{MPa}$, which is about 1.7 times greater than the stress at $20 \mathrm{~m}$, indicating that the peak value of the vertical stress decreases with the increase of the floor rock mass depth. From Fig. 4 it can be seen that, during the mining of the No.9 coal seam, when the working face advances to $60 \mathrm{~m}$, the maximum value of the vertical stress of the rock mass at the depth of $10 \mathrm{~m}$ below the floor is 2
$\mathrm{MPa}$, and that at a depth of $20 \mathrm{~m}$ below the floor is 2.12 $\mathrm{MPa}$. The stress is released when the No.8 coal seam is mined, and the maximum value of the vertical stress at the same layer of the floor is decreasedwhen the No.9 coal seam is mined.

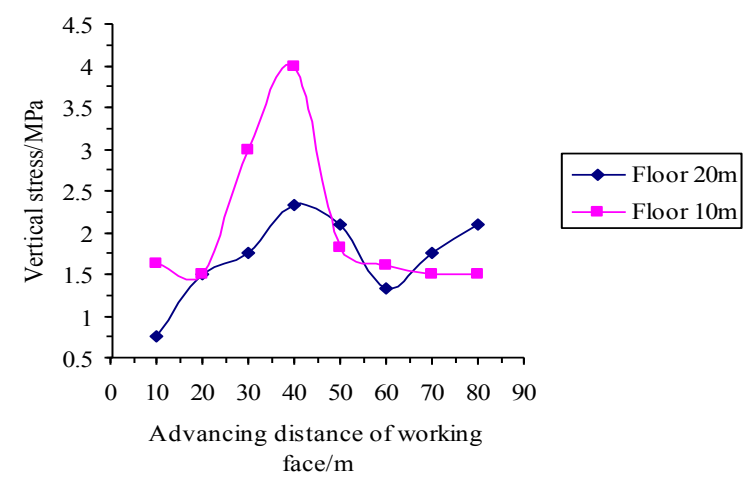

Fig.3. Distribution of floor stress at different depths when the No.8 coal seam is mined

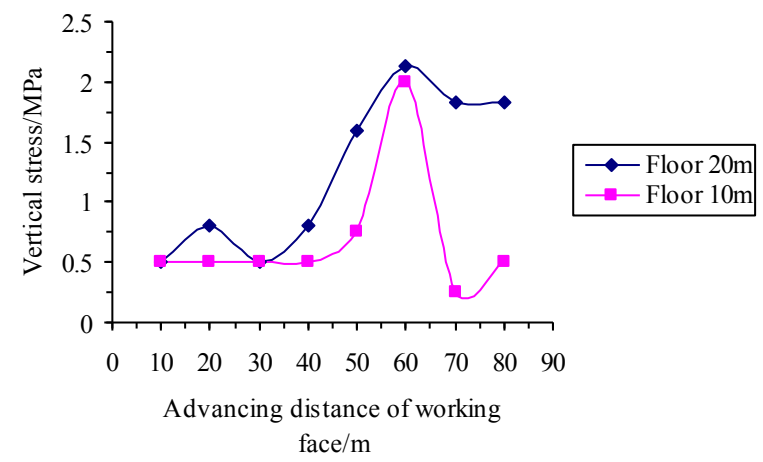

Fig.4. Distribution of floor stress at different depths when the No.9 coal seam is mined

\subsection{Floor rock mass movement characteristics}

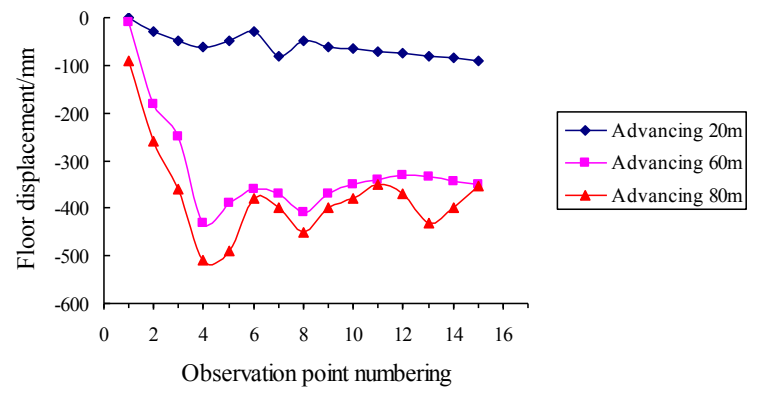

Fig.5. Floor rock mass displacement curve when the No.8 coal seam is mined

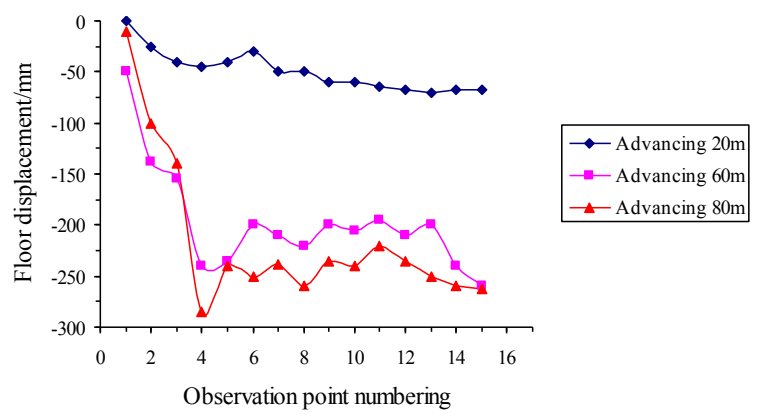

Fig.6. Floor rock mass displacement curve when the No.9 coal seam is mined 
From Fig. 5 and Fig. 6 it can be seen that the floor heave phenomenon of the coal seam floor becomes very apparent with the advance of the working face. The smaller the distance to the working face, the greater the amount of floor heave; furthermore, the more the working face advances, the greater the peak value of floor heave. During the mining of the No.8 coal seam, as the working face advance approaches $20 \mathrm{~m}$, the floor heave begins to increase gradually from 0 $\mathrm{mm}$ to a maximum of $85 \mathrm{~mm}$; when advancing to $60 \mathrm{~m}$, the maximum floor heave is $434 \mathrm{~mm}$; and when advancing to 80 $\mathrm{m}$, the maximum floor heave is $512 \mathrm{~mm}$. During the mining of the No.9 coal seam, when the working face advances to $20 \mathrm{~m}$, the maximum floor heave is $72 \mathrm{~mm}$; when advancing to $60 \mathrm{~m}$, the maximum floor heave is $248 \mathrm{~mm}$; and when advancing to $80 \mathrm{~m}$, the maximum floor heave is $286 \mathrm{~m}$. In the three advancing curves of 20,60 and $80 \mathrm{~m}$, change occurs near observation points 2,3 and 4 . The main reason for this is that the roof height at these observation points is large, and clear cracks are generated at the floor. This indicates that the energy released above the mined-out area is large, thereby causing the floor heave to increase.

\subsection{Lower coal group floor failure process and characteristics}

The simulation test results show that under the joint action of mining pressure and confined water, fissures are generated in the floor aquifuge, and expand and connect together (see Fig.7-Fig.9). As the development of partial fissures is not very obvious and cannot be shown clearly, the figures include close-ups to specifically show the failure process and characteristics of the lower coal group floor rock mass.

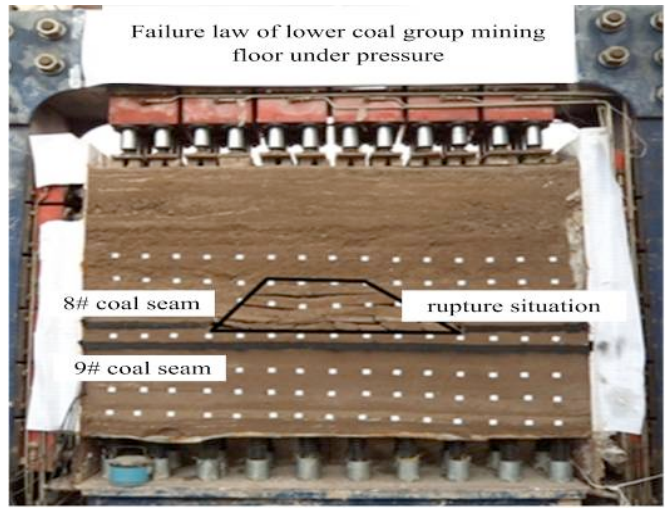

(a)

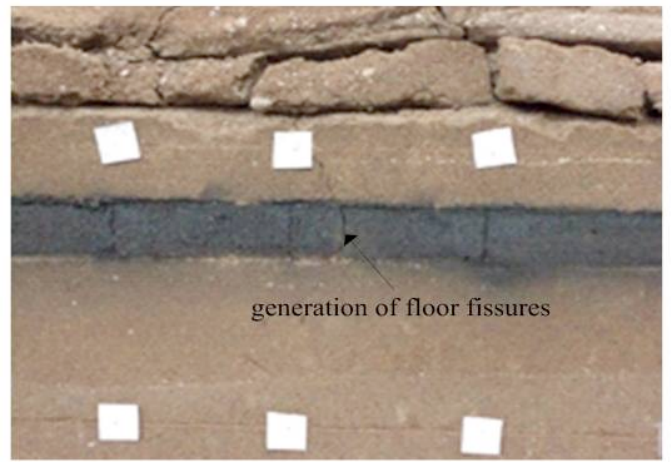

(b)

Fig.7. Floor failure situation when first significant failure occurs in the No.8 coal seam

When the working face advances to $27 \mathrm{~m}$, the preliminary rupture begins to appear on the centre floor rock strata of the mined-out area of the No.8 coal seam, and vertical fissures are generated, although the size is very small (see Fig. 7 (b)). When the working face advances to 40 $\mathrm{m}$, the length of the vertical fissures begins to increase significantly, and the original small fissures develop further. At this moment the failure is mainly tensile, and the failure depth is about $10 \mathrm{~m}$ away from the floor of the coal seam. As the working face continues to advance forward with time, the failure fissures in the floor rock strata of the coal seam continue to develop, the failure depth increases, and new fissures appear constantly.

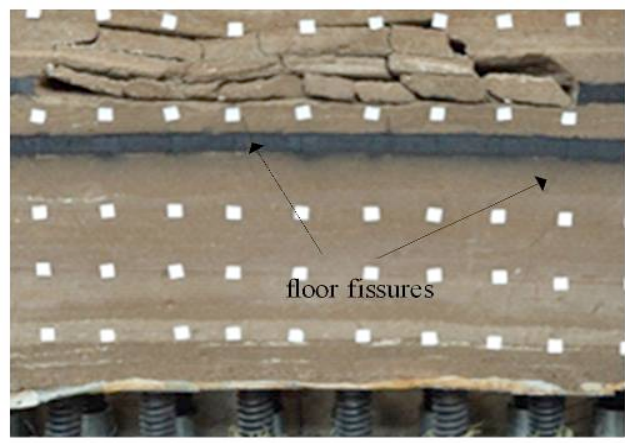

(a)

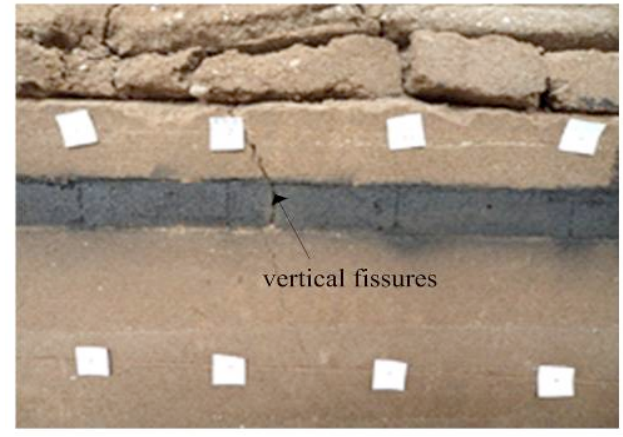

(b)

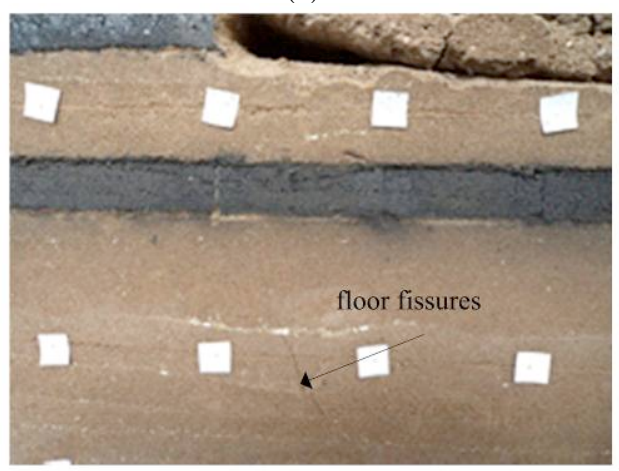

(c)

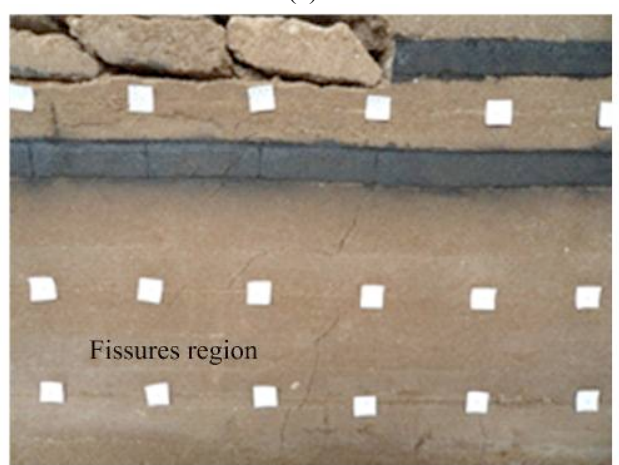

(d)

Fig.8. Failure situation of the No.8 coal seam floor with advancing of the working face 
When the working face advances to $80 \mathrm{~m}$, the fissures develop fully, and both bedding fissures and inclined fissures, with angles of $45-60^{\circ}$, develop in the horizontal direction, on a large scale in the working face cut-holes and in the vicinity of the protective coal pillars (see Fig.8 (b), (c) and (d)). The maximum depth of the fissure is about $21 \mathrm{~m}$ below the coal seam floor, and the horizontal length is about $10 \mathrm{~m}$. The analyses show that the inclined fissures are due to tensile failure of the floor rock mass under the joint action of water pressure and mining pressure, while the bedding fissures are caused by the inconsistencies between the upper and lower deformations of the rock strata.

After the mining of the No.8 coal seam was completed, we allowed the model to stand for two days to become stable, then we conducted the mining of the No.9 coal seam. It was shown that, as the working face gradually advances forward, the roof bulges downwards; at the same time, the overburden strata become more and more broken, and cavitation becomes more and more developed, as shown in Fig. 9. When the working face advances forward to $20 \mathrm{~m}$, the fissuring near the cut-hole coal wall begins to become significant, and the failure trend is more apparent (see Fig. 9 (c)).

When the working face advances forward to $80 \mathrm{~m}$, the fissures located below the coal pillars develop fully toward the deep section, with a maximum depth of $20 \mathrm{~m}$ from the coal seam floor. At the same time bedding fissures develop, up to 5-12 m long, and floor failure becomes more apparent. At both ends of the bedding fissures are strata-crossing fissures which incline toward the advancing direction of the working face, with dip angles of $45-70^{\circ}$. The strata-crossing fissures near the cut-hole coal wall incline toward the rear coal body (see Fig.9 (c) and (d)).

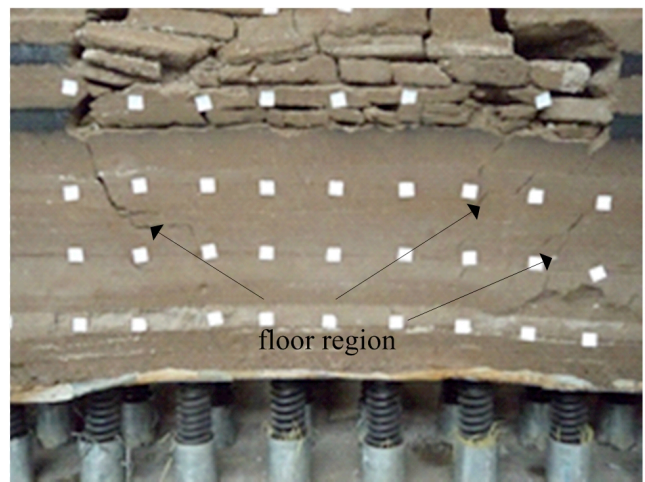

(a)

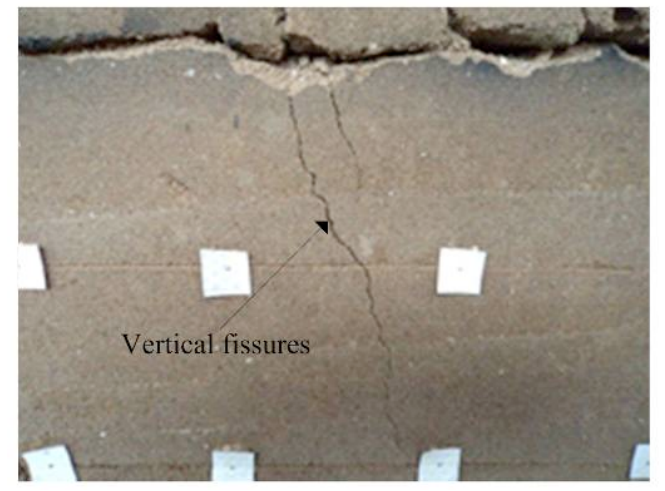

(b)

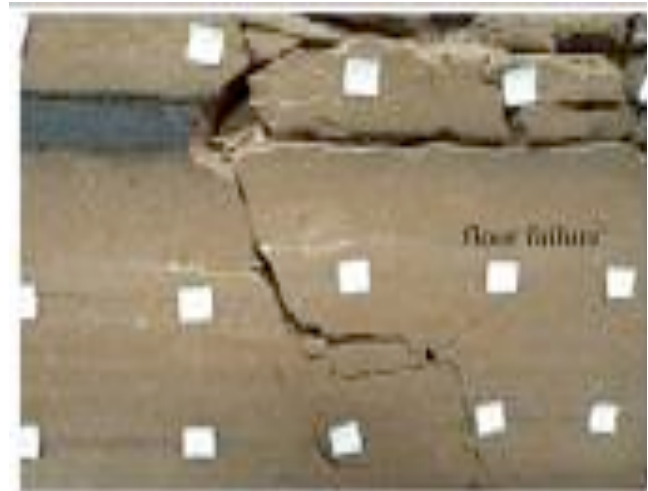

(c)

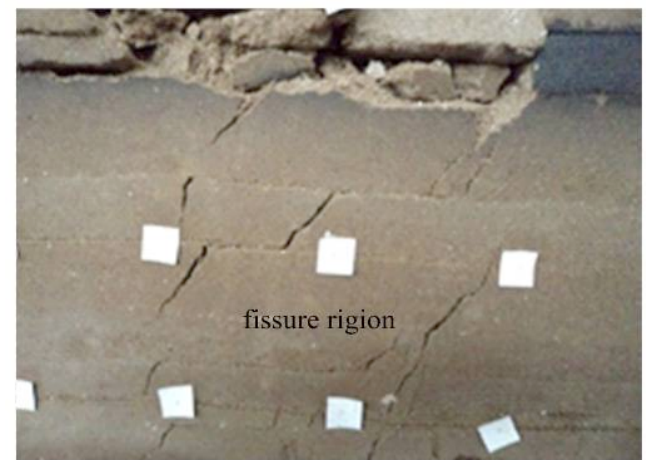

(d)

Fig.9. Failure situation of No.9 coal seam floor with advancing of working face

\section{Working face floor failure depth calculation}

The 'plate model' theory [10] is used to calculate the maximum depth of the mining floor failure zone. The calculation formulas are as follows:

$$
\begin{aligned}
& L_{m}=\frac{0.42 \gamma^{2} H^{2} L_{x}}{4 \sigma_{c}^{2}} \\
& x_{a}=\frac{m}{2 K_{1} \tan \varphi} \ln \frac{n \gamma H+C_{m} \cot \varphi}{K_{1} C_{m} \cot \varphi} \\
& h_{1}=\frac{x_{a} \cos \varphi_{0}}{2 \cos \left(\frac{\pi}{4}+\frac{\varphi_{0}}{2}\right)} e^{\left(\frac{\pi}{4}+\frac{\varphi_{0}}{2}\right) \tan \varphi_{0}}
\end{aligned}
$$

In the formulas $L_{m}$ is the distance of the maximum failure depth to the working face, $L_{x}$ is the mining length of the working face, $\gamma$ is the rock mass bulk density, $H$ is the mining depth, $m$ is the mining thickness, $x_{a}$ is the width of the coal body edge plastic zone, $\varphi$ is the internal friction angle, $C_{m}$ is the cohesion, $n$ is the maximum stress concentration coefficient, $h_{1}$ is the maximum depth of the plastic failure zone and $\varphi_{0}$ is the average internal friction angle of the floor rock mass weights.

The actual parameters of the Shuangliu Coal Mine project are substituted into formulas (5)-(7). After the calculation has been performed, the maximum depth of the working face floor failure zone during normal mining of the lower coal group is shown to be $21.96 \mathrm{~m}$. 


\section{Conclusions}

1) With the constant advance of the working face, the lower coal group floor rock mass successively undergoes the three stages of 'stress increase', 'stress decrease' and 'gradual recovery'. At the same time, the maximum value of the vertical stress of the floor decreases with the increase of the floor rock mass depth. With the constant advance of the working face, the floor heave of the floor becomes apparent, and the greater the advance is, the greater the maximum value of the floor heave.

2) Under the joint action of mining and floor water pressure, the floor failure region first appears in the centre of the mined-out area, and the failure depth is small; the failure depth and area expand further with further mining, and the failure regions are mainly concentrated in the coal walls and the vicinity below the cut-holes. When the No.8 coal seam is mined, the maximum failure depth of the working face floor is about $21 \mathrm{~m}$; when the No.9 coal seam is mined, the maximum failure depth of the working face floor is about 20 $\mathrm{m}$.

\section{Acknowledgements}

This research is supported by the Specialized Research Foundation for the Doctoral Program of Higher Education of China under grant 20114116120005, National Natural Science Foundation of China (No. 51374093,51104058), National Basic Research Program of China(Grant No. 2013CB227903).

\section{References}

[1]. Zhang J. C., Shen B. H. "Coal mining under aquifers in China: a case study", International Journal of Rock Mechanics and Mining Sciences, 41(4), 2004, PP.629-639.(in Chinese)

[2]. Wang Z. Y., Liu H. Q. "Coal mining above confined aquifer". Beijing: China Coal Industry Publishing House, 1992. (in Chinese)

[3]. Jiang Y. D., Lu Y. K., Zhao Y. X., et al. "Similar simulation test for breakage law of working face floor in coal mining above aquifer", Chinese Journal of Rock Mechanics and Engineering, 30(8), 2011, pp.1571-1578. (in Chinese)

[4]. Zhao Y. X., Jiang Y. D., Lu Y. K., et al. "Similar simulation experiment of bi-directional loading for floor destruction rules in coal mining above aquifer", Journal of China Coal Society, 38(3), 2013, pp.387-390. (in Chinese)

[5]. Gong P. L., Hu Y. Q., Zhao Y. S., et al. "Three-dimension simulation study on law of deformation and breakage of coal floor on mining above aquifer", Chinese Journal of Rock Mechanics and Engineering, 24(23), 2005, pp.4396-4402. (in Chinese)
[6]. Wang J. A., Wei X. H., Ji H. G.. "Rupture and seepage law of rooffloor strata caused by coal mining between double-bearing aquifers",Journal of China Coal Society, 37(6), 2012, pp.891-897. (in Chinese)

[7]. Hu Y. Q., Yan G. C., Shi X. W. "Study on physical and numerical simulation of water inrush prediction theory for coal mining above confined aquifer", Chinese Journal of Rock Mechanics and Engineering, 27(1), 2008, pp.9-15. (in Chinese)

[8]. Wang J. M. "In-situ measurement and physical analogue on water inrush from coal floor induced by progressive intrusion of artesian water into protective aquiclude", Chinese Journal of Geotechnical Engineering, 21(5), 1999, 546-549. (in Chinese)

[9]. Feng M. M., Mao X. B., Bai H. B. et al. "Experimental research on fracture evolution law of water-resisting strata in coal seam floor above aquifer", Chinese Journal of Rock Mechanics and Engineering, 28(2), 2009, pp.336-341. (in Chinese)

[10]. Peng S. P., Wang J. A. Safety coal mine above the confined aquifer. Beijing: China Coal Industry Publishing House, 2001. (in Chinese) 